https://doi.org/10.25208/0042-4609-2019-95-5-58-67

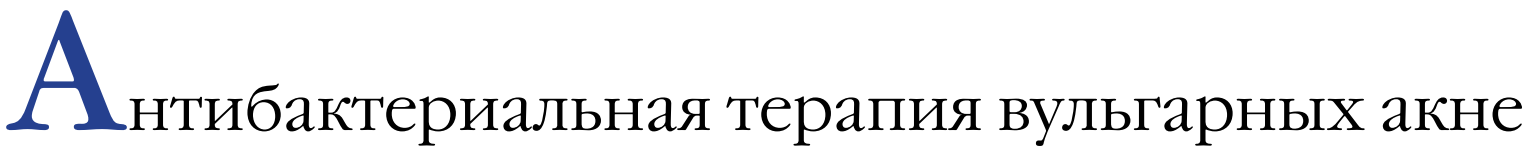

Снарская Е. С.

Первый Московский государственный медицинский университет им. И. М. Сеченова (Сеченовский университет) Министерства здравоохранения Российской Федерации 119435, Российская Федерация, г. Москва, ул. Большая Пироговская, д. 4, к. 1

Цель: оценить эффрективность и переносимость миноциклина в терапии среднетяжелых и тяжелых форм acne vulgaris в соответствии с современными представлениями о патогенезе заболевания. Материалы и методы. Проведено долгосрочное многоцелевое наблюдение, в которое было включено 28 пациентов с установленным диагнозом acne vulgaris, среднетяжелые и тяжелые формы. Пациенты получали монотерапию лекарственным препаратом Минолексин ${ }^{\circledR}$ в зависимости от степени тяжести 50-100 мг в сутки. До начала исследования и после окончания лечения проводился осмотр больного с подсчетом высыпных элементов, клинический и биохимический анализ крови, исследование функции сальных желез, лазерная сканирующая микроскопия, лазерная доплеровская фрлоуметрия, определение дерматологического индекса качества жизни, фотографирование (при согласии пациента). В процессе терапии проводился осмотр больного и оценка переносимости препарата.

Результаты. Получены доказательства эфффективности миноциклина в лечении вульгарных акне средней и тяжелой степени тяжести, что подтверждается визуальными дерматологическими показателями, неинвазивными методами исследования (результаты себуметрии, конфрокальной лазерной сканирующей микроскопии, доплеровской фрлометрии), показателями дерматологического индекса качества жизни. При изучении клинических и лабораторных показателей не выявлено проблем безопасности. Нежелательные явления в процессе исследования не зарегистрированы. Заключение. Минолексин ${ }^{\circledR}$ (миноциклин) является высокоэфрфективным и безопасным препаратом для лечения вульгарных акне средней и тяжелой степени тяжести и может быть рекомендован для практического применения в амбулаторной практике.

Ключевые слова: acne vulgaris, вульгарные акне, патогенез, антибактериальная терапия, минолексин

Конфрликт интересов: автор заявляет об отсутствии потенциального конфликта интересов, требующего раскрытия в данной статье.

Для цитирования: Снарская Е. С. Антибактериальная терапия вульгарных акне. Вестник дерматологии и венерологии. 2019;95(5):58-67. https://doi.org/10.25208/0042-4609-2019-95-5-58-67 


\section{Antibacterial therapy of vulgar acne}

Elena S. Snarskaya

I. M. Sechenov First Moscow State Medical University, Ministry of Health of the Russian Federation

Bolshaya Pirogovskaya str., 4, korpus 1, Moscow, 119435, Russian Federation

Purpose: to evaluate the efficacy and safety of minocycline in the therapy of medium-heavy and severe forms of acne vulgaris according to modern ideas about pathogenesis of the disease.

Materials and methods. Long-term multi-purpose observation which included 28 patients with the established diagnosis of acne vulgaris, medium-weight and severe forms is made. Patients received monotherapy by Minoleksin ${ }^{\circledR}$ medicine, depending on severity - 50-100 mg a day. Prior to the research and after the end of treatment inspection of the patient with calculation the rash elements, clinical and biochemical blood analysis, a research of function of sebaceous glands, the laser scanning microscopy, a laser Doppler floumetry, definition of the dermatological index of quality of life, photography (was performed at the consent of the patient). In the course of therapy inspection of the patient and assessment of tolerance of drug was performed.

Results. The evidence of efficiency of minocycline in treatment of vulgar acnes of average and heavy severity is obtained that is confirmed by visual dermatological indicators, non-invasive methods of a research (results of a sebumetriya, the confocal laser scanning microscopy, a Doppler floumetriya), indicators of the dermatological index of quality of life. When studying clinical and laboratory indicators security concerns are not revealed. The undesirable phenomena in the course of the research are not registered. Conclusion. Minolexin ${ }^{\circledR}$ (minocycline) is highly effective and safe drug for treatment of vulgar acnes of average and heavy severity and it can be recommended for practical application in out-patient practice.

Keywords: acne vulgaris, vulgar acne, pathogenesis, antibacterial therapy, minolexin

Conflict of interest: the author states that there is no potential conflict of interest requiring disclosure in this article.

For citation: Snarskaya E. S. Antibacterial therapy of vulgar acne. Vestnik Dermatologii i Venerologii. 2019;95(5):5867. https://doi.org/10.25208/0042-4609-2019-95-5-58-67 
Акне обыкновенные (acne vulgaris, или угри обыкновенные) - хроническое воспалительное заболевание, проявляющееся открытыми или закрытыми комедонами и воспалительными поражениями кожи в виде папул, пустул, узлов [9].

Акне - это мультифракториальный дерматоз, в патогенезе которого большую роль играют генетически обусловленная гиперандрогения и генетически детерминированный тип секреции сальных желез [9]. Обыкновенные акне являются распространенным хроническим заболеванием сально-волосяных фолликулов, чаще встречающимся в пубертатном периоде и резко снижающим качество жизни больных [1-3]. Пациенты с акне составляют основной контингент врачей - дерматологов и косметологов, при этом лекарственная терапия этого дерматоза требует вложения большого количества денежных средств. Сложный патогенез заболевания требует детального изучения, и современные исследования расширяют представление о патогенезе акне, отклоняясь от предшествующих тенденций в сторону выделения какого-либо одного главного фактора, как это было ранее (например, только доминирующая роль андрогенов) [10]. Благодаря современным инновационным молекулярно-биологическим исследованиям получены убедительные данные о наличии субклинического воспаления как основного звена патогенеза акне. По результатам исследования Do T.T. и соавт., в 28 \% случаях воспалительные элементы акне развивались de novo, минуя стадию комедонов [1]. В свою очередь, Kircik L.H. и соавт. предложили новую концепцию патогенеза акне, согласно которой воспаление предшествует образованию комедонов и гиперкератинизации $[2,3]$. Было установлено, что воспаление в сально-волосяном фолликуле возникает еще до формирования элементов сыпи и проявляется значительным повышением количества CD4+-T-лимфоцитов, макрофрагов, экспрессии ИЛ-1 и а-интегринов [2, 3]. Особого внимания заслуживает тот фракт, что повышение маркеров воспаления происходит как в месте последующего формирования элементов акне, так и в нормальной коже. Результаты этого исследования позволили сделать предположение, что традиционно считавшиеся «невоспалительными» микрокомедоны, открытые и закрытые комедоны, в действительности являются воспалительными [2, 3]. В подтверждение данной концепции можно привести результаты, полученные в других исследованиях. Например, согласно данным Leeming J. и соавт., в норме лишь из $12 \%$ фролликулов выделяются Cutibacterium acnes (ранее называвшиеся Propionibacterium acnes), количество стафилококков в фролликулах, в основном S. epidermidis, составляет около $4 \%$, грибов Malassezia - $13 \%$, а не менее трети фролликулов и 20-54 \% папулезных элементов акне стерильны $[4,5]$. По данным Leeming J. и соавт. [5], в норме лишь из $12 \%$ фолликулов выделяются $P$. acnes.

Согласно классификации, предложенной Американской академией дерматологии, выделяют легкую степень акне (наличие закрытых и открытых комедонов, до 10 папул), среднюю (многочисленные комедоны, единичные или многочисленные папулы и до 10 пустул, единичные узелки), тяжелую (многочисленные комедоны, множественная папуло-пустулезная сыпь, до трех узлов) и очень тяжелую (выраженная воспалительная реакция в глубоких слоях дермы с формиро- ванием множественных болезненных узлов, кист, фристул и рубцов [6].

Показано, что частота возникновения акне у ребенка превышает 50 \%, если они присутствуют у обоих родителей, при этом подчеркивается важная роль наследования повышенного синтеза андрогенов. Однако генетические фракторы могут играть важную роль в развитии заболевания сальных желез только в том случае, когда на генетическую предрасположенность наслаивается воздействие других факторов окружающей среды. Несмотря на отсутствие единого представления об этиологии и патогенезе акне, важную роль в возникновении данного заболевания играет целый ряд взаимосвязанных патогенетических фракторов, к которым безусловно относятся: нарушение качественных и количественных параметров кожного сала, изменения гормонального статуса, патологическая кератинизация фолликулярного канала, интенсивная колонизация Cutibacterium acnes (C. acnes) протоков сальных желез, развитие воспалительной реакции в перифолликулярных зонах [1-5]. Ключевым механизмом в запуске воспалительных изменений при этом выступают C. acnes, микробные липазы которых, выделяемые при избыточной пролиферации, способствуют образованию свободных жирных кислот, повреждающих стенку сально-волосяного фолликула с последующим воспалением и пустулизацией. Размножение $C$. acnes приводит к повышению активности метаболических процессов, следствием которых является выделение медиаторов воспаления, ответственных за воспалительный процесс. Провоспалительные цитокины активируют фрермент циклооксигеназу, в результате чего запускается воспалительная реакция, проявляющаяся на коже в виде папул, пустул, узлов и кист. Вместе с тем относительно недавно на поверхности кератиноцитов были обнаружены толл-подобные рецепторы (TLR), на которых фиксируются $C$. acnes, запускающие каскад воспалительных реакций. Предполагается, что процессу гиперкератинизации предшествует воспаление, т. к. компоненты клеточной стенки C. acnes связываются с TLR на мембране макрофрагов, что стимулирует выработку различных цитокинов [4]. Таким образом, C. acnes принимают участие во многих процессах, имеющих место в патогенезе вульгарных акне, включая воспаление, гиперкератоз и избыточную продукцию себума, что обуславливает необходимость их эрадикации и является важным компонентом успешной терапии. Тактика лечения больных вульгарными акне определяется клинической формой и тяжестью заболевания, возрастом и полом больного, сопутствующими заболеваниями, эфффективностью предшествующей терапии, особенностями течения и длительностью рецидивов. Выбор системных антибактериальных препаратов и линий лечебного ухода за кожей основан прежде всего на квалифицированной оценке стадии заболевания с обязательным учетом индивидуальных особенностей каждого больного. При длительном течении заболевания с частыми обострениями процесса даже легкая и средняя степени тяжести акне могут привести к фрормированию симптомокомплекса постакне, при этом особую сложность в терапии представляет сочетание первичных островоспалительных элементов акне, возникающих на фоне вторичных изменений кожи. В таких случаях добиться выраженного 


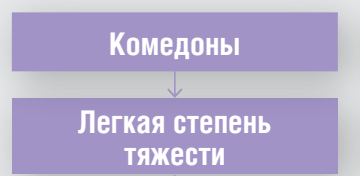

Монотерапия топическими ретиноидами, азелаиновой кислотой, салициловой кислотой

$$
\begin{gathered}
\text { При } \\
\text { неудовлетворительном } \\
\text { результате смена } \\
\text { препаратов }
\end{gathered}
$$

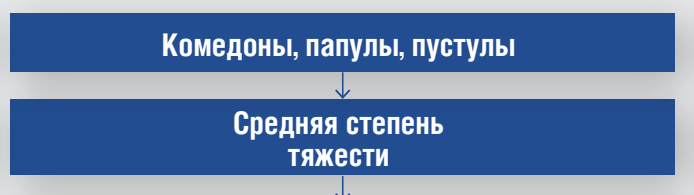

Топические ретиноиды + бензоилпероксид

Топические ретиноиды + топические антибиотики Топические ретиноиды + бензоилпероксид + топические антибиотики

Азелаиновая кислота + бензоилпероксид Азелаиновая кислота + топические ретиноиды

При неудовлетворительном результате топические ретиноиды + курсы антибиотикотерапии Топические ретиноиды + КОК

Топические ретиноиды + системные ретиноиды
Узлы, кисты, флегмоны

Тяжелая степень
тяжести

Курсы системной антибактериальной терапии + наружная терапия для средней тяжести акне

Системные ретиноиды + наружная терапия для средней тяжести акне

Системные ретиноиды + наружная терапия для средней тяжести акне + обкалывание ГКС

Поддерживающая терапия одним из препаратов для легкой степени тяжести +

рациональный уход + фризиотерапия + косметологические процедуры

Рис. 1. Алгоритм терапии акне в зависимости от степени тяжести

Fig. 1. Acne therapy algorithm based on its severity

косметического эфрфекта достаточно сложно и воздействовать на кожу следует последовательно и длительно, в течение нескольких сроков обновления эпителия. В лечении множественных диссеминированных папуло-пустулезных или инфильтративных, узловато-кистозных фрорм заболевания целесообразно проведение антибактериальной терапии [7]. Длительность применения системных антибиотиков обычно составляет 6-8 недель (максимально 18 недель), при неэфффективности которой целесообразно применение системных ретиноидов. Согласно Европейским рекомендациям, в лечении средних и среднетяжелых форм вульгарных акне целесообразно сочетать пероральный прием антибиотиков с наружными средствами, содержащими ретиноиды или бензоила пероксид, у женщин возможно их сочетание с гормональной терапией. Кроме того, не следует одновременно назначать антибактериальные препараты для топического и системного применения [7]. Важная и неотьемлемая составляющая комплексной терапии акне - ежедневный уход за кожей с помощью средств противоугревой лечебной косметики, не содержащей спирты и не обладающей комедогенными свойствами.
При легком течении дерматоза, как правило, назначается только наружная терапия, а при среднетяжелом и тяжелом течении - системная терапия (рис. 1).

Антибиотики группы тетрациклина, включающие доксициклин, тетрациклин, миноциклин, являются основными в схемах лечении акне (табл. 1) [7, 8].

Миноциклин отличается целым рядом преимуществ, является высокоэффрективным препаратом первой линии для лечения среднетяжелых и тяжелых форм acne vulgaris и включен в Европейские рекомендации по лечению акне [7, 8].

В 2006 г. FDA одобрило новые расширенные рекомендации по применению миноциклина в лечение вульгарных акне на основании изучения многолетнего опыта применения препарата в странах Европы [7, 8]. Так, на основании клинического исследования с использованием трех дозировок миноциклина для лечения вульгарных акне (1, 2 и 3 мг/кг/сут) и плацебо было показано, что эфффективность во всех трех группах сопоставима, однако при применении дозировки 1 мг/кг/сут побочные эфрфекты сравнимы с плацебо, что демонстрирует высокую эффективность миноциклина в малых дозах и его отличную переносимость [8].

Таблица 1. Системные антибиотики в лечении акне

Table 1. Systemic antibiotics for treating acne

\begin{tabular}{cccc}
\hline Препарат & Дозы & Эфрективность & Недостатки \\
\hline & \multicolumn{2}{c}{ Препараты первой линии } & - \\
\hline Миноциклин & $100-200$ мг в день & +++ & Фоточувствительность \\
\hline Доксициклин & $100-200$ мг в день & ++ & Плохая абсорбция с пищей \\
\hline Тетрациклин & 500 мг 2 раза в день & Альтернативные препараты & - \\
\hline Эритромицин & \multicolumn{2}{c}{} \\
\hline
\end{tabular}




\section{Материалы и методы}

С целью оценки эфрфективности и переносимости миноциклина в терапии среднетяжелых и тяжелых форм acne vulgaris проведено долгосрочное многоцелевое наблюдение, в которое было включено 28 пациентов. Сроки наблюдения составили 45 дней ( \pm 2 дня).

В Российской Федерации с 2012 г. зарегистрирован и успешно применяется единственный препарат миноциклина - Минолексин ${ }^{\circledR}$ капсулы, 50 и 100 мг (производитель $A O$ «АВВА-РУС», Россия).

Характеристика лекарственного препарата миноциклин (Минолексин ${ }^{\circledast}$ )

Миноциклин является полусинтетическим антибиотиком второго поколения группы тетрациклинов.

Миноциклин обладает выраженным бактериостатическим эффректом, нарушая синтез белка в клетках грамположительных и грамотрицательных микроорганизмов. По отношению к ряду патогенов минолексин проявляет гораздо большую противомикробную активность, чем другие тетрациклины. In vitro миноциклин ингибирует рост золотистого и коагулазонегативного стафиллококка, в частности метициллинрезистентного золотистого стафилокока и метициллинрезистентного штамма S. epidermis [8].

Миноциклин имеет длительный период полувыведения (приблизительно 16 4), а максимальная концентрация в плазме крови и тканях составляет до 4 раз выше, чем при лечении другими препаратами группы тетрациклинов. Эквивалентный уровень в крови и тканях достигается как при пероральном, так и при внутривенном способе введения.

В сравнении с тетрациклином и доксициклином концентрация миноциклина в коже на $47 \%$ выше, чем в сыворотке крови, так как он отличается способностью к кумуляции в дерме, кроме того, высокая липофильность препарата усиливает его способность проникать непосредственно в сальные железы, что обеспечивает быстрое наступление клинического улучшения. Молекула миноциклина в сравнении с другими тетрациклинами обладает наиболее выраженными липофильными свойствами, что обусловливает отличия в фрармакокинетике от остальных препаратов данной группы и дает способность проникать через липидный слой бактерий.

Применение минолексина практически не несет риска возникновения антибиотикорезистентных штаммов в отличие от других представителей группы тетрациклинов, применение которых может привести к развитию толерантности к проводимому лечению. Одним из механизмов развития устойчивости к антибактериальным препаратам является увеличение липидного слоя клеточной стенки бактерии, что, в свою очередь, приводит к затруднению проникновения молекул антибиотика в клетку патогенов.

Фоточувствительность пациентов при применении препаратов миноциклина проявляется в меньшей степени, чем при лечении другими препаратами группы тетрациклинов, что позволяет проводить курс терапии данным препаратом независимо от времени года.

Миноциклин обладает высокой комплаентностью благодаря удобному режиму дозирования - суточная доза применяется в один или два приема по сравнению с более частой схемой приема других представителей тетрациклинов. Минолексин ${ }^{\circledR}$ разрешен к применению у детей с 8 лет, обладает комфортным режимом дозирования при лечении acne vulgaris (50 мг 1раз в день), что позволяет минимизировать возможные побочные эфрфекты.

Высокая растворимость и всасываемость минимизируют эффект абсорбции с пищей, что позволяет принимать препарат во время еды.

Характеристика пациентов

В исследование было включено 28 пациентов с установленным диагнозом acne vulgaris, среднетяжелые и тяжелые формы в возрасте от 13 до 35 лет, в среднем 23,76 + 4,59 года, мужчин - 12, женщин - 16 .

\section{Критерии включения:}

- пациенты обоего пола с диагнозом вульгарные угри средней и тяжелой степени тяжести;

- отсутствие приема системных ретиноидов, антибактериальной и/или любой другой системной терапии не менее чем за 60 дней до начала исследования;

- отсутствие тяжелой соматической или психической патологии;

- информированное согласие участников на участие в исследовании.

Критерии исключения:

- дети до 14 лет;

- беременные и кормящие женщины;

- пациенты, не желающие отменять другие лекарственные средства;

- индивидуальная непереносимость компонентов миноциклина;

- пациенты, страдающие порфирией, системной красной волчанкой или пациенты с тяжелой печеночной или почечной недостаточностью, лейкопенией;

- несоблюдение правил применения миноциклина, предписанного врачом.

Распределение по клинико-морфологическим формам согласно Европейской классификации (XX Всемирный конгресс по дерматологии, 2002 г.):

легкая степень (1) - наличие открытых и закрытых комедонов и менее 10 папуло-пустулезных элементов;

средняя степень (2) - наличие более 10, но менее 40 папуло-пустулезных элементов;

тяжелая степень (3) - более 40 папуло-пустулезных элементов, а также узлы и кисты.

\section{Дизайн исследования}

Дерматологический осмотр проводился визуально с простым подсчетом высыпных элементов: папул, пустул и узлов, на основании чего определялась степень тяжести. У 22 (78,6 \%) больных была определена средняя степень тяжести, у 6 (21,4 \%) - тяжелая степень. Длительность заболевания в среднем составила 7,93 \pm 4,86 года. Дебют заболевания отмечался в возрасте $13,78 \pm 2,25$ года.

Все пациенты получали монотерапию лекарственным препаратом Минолексин ${ }^{\circledR}$, пациенты со среднетяжелыми формами acne vulgaris - 50 мг в сутки, с тяжелыми формами - 100 мг в сутки. В качестве дополнительного ухода все больные получали гель для умывания для проблемной кожи.

До начала исследования и после окончания лечения (45 \pm 2 дня) проводился осмотр больного с подсчетом высыпных элементов, клинический и биохимический анализ крови, исследование функции сальных желез (себуметрия), лазерная сканирующая микроскопия (КЛСМ) (у 10 больных), лазерная доплеровская 
флоуметрия (ЛДФ), определение дерматологического индекса качества жизни (ДИКЖ), фотографирование (при согласии пациента). Основным критерием выбора данных методов обследования была их неинвазивность, возможность изучить патоморфологические изменения, происходящие в коже, без нарушения ее целостности, что имеет особое значение ввиду типичных локализаций высыпаний в эстетически значимых зонах лица. В процессе терапии (на $20 \pm 2$ дня) проводился осмотр больного и оценка переносимости препарата.

\section{Методы обследования}

Дерматологический осмотр проводился визуально с простым подсчетом высыпных элементов: папул, пустул и узлов, на основании чего определялась степень тяжести.

Изучение гематологических показателей (гемоглобин, гематокрит, количество эритроцитов, средний объем эритроцитов, количество лейкоцитов, тромбоцитов, скорость оседания эритроцитов, лейкоцитарная фрормула) проводили с помощью общеклинических методов исследования на автоанализаторе JENSKulter (США) в клинической лаборатории Первого МГМУ им. И.М. Сеченова.

Биохимические исследования крови изучали по следующим показателям: общий белок, глюкоза, креатинин, общий билирубин, холестерин, мочевая кислота, аспарагиновая и аланиновая трансаминазы (АСТ и АЛТ), гамма-глутамилтрансфераза ( $\gamma$-ГТ), лактатдегидрогеназа (ЛДГ) и выполнялись на автоанализаторе Konelab 30i (Швейцария) в биохимической лаборатории Первого МГМУ им. И.М. Сеченова.

Всем пациентам с целью объективной оценки клинических данных было проведено комплексное исследование фризиологических параметров. Для этого применялся неинвазивный метод диагностики - себуметрия, основанный на фротометрическом анализе сальных пятен. Исследование проводилось при помощи аппарата Cutometer MPA 580 CK electronic (Германия) с насадками для себуметрии. Лазерная сканирующая микроскопия (КЛСМ) проводилась на микроскопе MAVIG Vivascope 1500, Германия/США). Основным критерием выбора данных методов обследования была их неинвазивность, возможность изучить патоморфологические изменения, происходящие в коже, без нарушения ее целостности, что имеет особое значение ввиду типичных локализаций высыпаний в эстетически значимых зонах лица.

\section{Оценка дерматологического индекса качества}

\section{жизни больных}

Оценка качестважизнибольныхпроводиласьприпомощи специальной анкеты, разработанной F.Y. Finlay (Уэльский университет, Великобритания) и русифрицированной и валидизированной проф. Н.Г. Кочергиным. Применяется дерматологами для оценки степени негативного влияния кожного заболевания на различные аспекты жизни больного, характеризующие в целом его качество жизни (чем выше индекс - тем ниже качество жизни больного). ДИКЖ может быть использован как один из критериев оценки эфффективности терапии кожного заболевания у конкретного больного.

Данная анкета состоит из 10 вопросов, которые показывают связь с различными аспектами жизни больного: профессиональные, бытовые, сексуальные, социальные, личностные.

\section{Вопросы пациентам для определения ДИКЖ}

1. Испытывали ли Вы зуд, жжение или болезненность на прошлой неделе?

2. Испытывали ли Вы ощущение неловкости или смущение в связи с состоянием Вашей кожи?

3. Как сильно Ваши проблемы с кожей мешали Вам заниматься уборкой дома или покупками?

4. Насколько сильно состояние Вашей кожи влияло на выбор Вашего гардероба на прошлой неделе?

5. Как сильно влияло состояние Вашей кожи на Ваш досуг и социальную активность на прошлой неделе?

6. На прошлой неделе состояние Вашей кожи мешало Вам заниматься спортом?

7. Пропускали ли Вы учебу, отсутствовали на работе из-за состояния Вашей кожи? Если Вы ответили «нет», то насколько сильно Вас беспокоило состояние Вашей кожи, когда вы находились на работе или учебе?

8. Влияло ли состояние Вашей кожи на Ваши отношения с родственниками, партнерами, друзьями на прошлой неделе?

9. Насколько сильно Ваши проблемы с кожей влияли на Вашу сексуальную жизнь?

10. На прошлой неделе насколько сильно лечение заболевания кожи причиняло Вам неудобства, отнимало время, создавало проблемы?

На каждый вопрос предлагается 4 варианта ответа, каждый из которых оценивается соответственно от 0 до 3 баллов. Максимальная сумма баллов может равняться 30, при этом качество жизни пациента обратно пропорционально сумме баллов. Интерпретация значений ДИКЖ:

0-1 балл - нет влияния на жизнь пациента.

2-5 баллов - заболевание оказывает незначительное влияние на жизнь пациента.

6-10 баллов - заболевание оказывает умеренное влияние на жизнь пациента.

11-30 баллов - заболевание оказывает очень сильное влияние на жизнь пациента.

21-30 баллов - заболевание оказывает чрезвычайно сильное влияние на жизнь пациента.

Дерматологический индекс качества жизни может быть использован как критерий оценки тяжести состояния больного и как критерий эфффективности проводимой терапии. Снижение индекса в процессе лечения означает улучшение качества жизни больного.

Для статистической обработки данных использовались стандартные методы описательной и вариационной статистики, с использованием простого и множественного линейного регрессионного анализа. Значения рассчитывались и представлялись в виде $M \pm m_{M}, M \pm s$, $P \pm m_{P} n r \pm m_{R}$, где $M-$ среднее арифрметическое, $P$ относительные величины, выраженные в процентах $(\%), r$ - коэффрициент корреляции, $m(s)$ - ошибка репрезентативности (среднее квадратичное отклонение). При сравнении двух выборок друг с другом использовали непараметрический тест Уилкоксона. Различия значений считали достоверными при уровне вероятности более $95 \%(p<0,05)$.

\section{Результаты и обсуждение}

После проведенного курса лечения миноциклином у всех $(n=28)$ пациентов уменьшилось количество высыпных элементов. У пациентов со среднетяжелыми формами заболевания количество папуло-пустулезных снизилось 
с 28,2 $\pm 4,3$ до $2,5 \pm 0,8$, с тяжелыми формами - с $42,5 \pm$ 3,5 до 5,2 $\pm 1,3 ;$ узлов - с 3,02 $\pm 0,4$ до 0,6 $\pm 0,2$.

В результате проведенной терапии у 20 (91\%) больных со средней степенью тяжести больных была достигнута клиническая ремиссия (рис. 2 А, Б), у 2 (9 \%) больных отмечено значительное улучшение. У 5 (83,3 \%) больных с тяжелым течением вульгарных акне отмечалось значительное улучшение и у одного больного (16,7 \%) - улучшение (рис. 3 А, Б).

До лечения средний показатель себуметрии значительно превышал норму, что подтверждает повышение салоотделения у больных с вульгарными угрями и жирную себорею. После проведенного лечения показатели себуметрии значительно улучшились, снижаясь в зоне подбородка с 76 до 61 у.е., щек - с 65 до 50 у.е. и лба с 81 до 68 у.е. Таким образом, после курса терапии наблюдалась выраженная тенденция к нормализации салоотделения.

При анализе гемограммы и биохимических показателей крови до и после лечения не было отмечено никаких статистически достоверных отклонений (различие с контролем достоверно при $p<0,05)$. После проведенного лечения все средние значения оставались в пределах тех же значений (табл. 2 и 3). В лейкоцитарной формуле выявлялись относительный лимфоцитоз у 3 больных, эозинофилия - у 2 больных $(p>0,05)$.
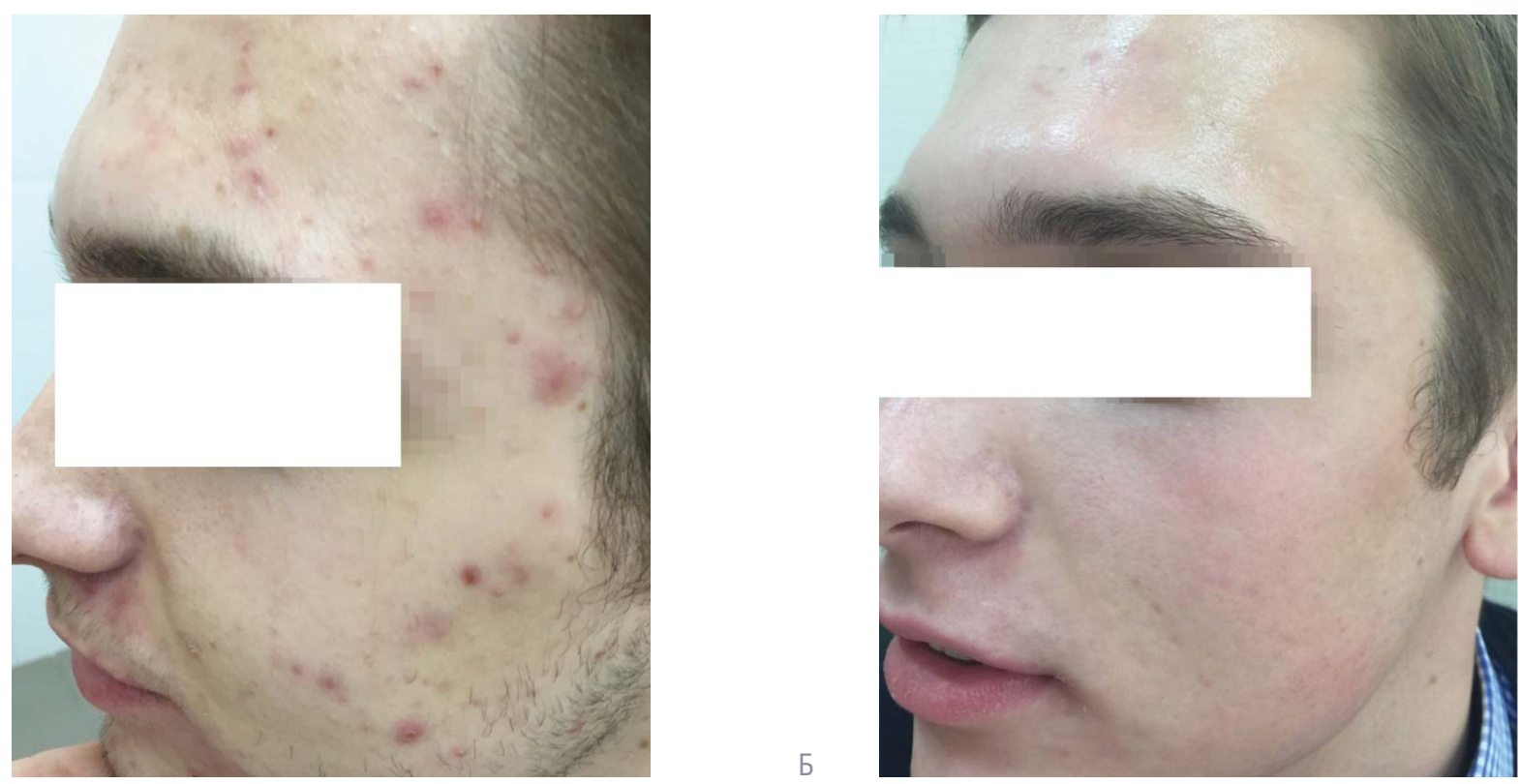

Рис. 2. Больной Е., 19 лет: А — вульгарные угри, средняя степень до лечения; Б — вульгарные угри, средняя степень после лечения

Fig. 2. Patient $E$., 19 years old. $A$ - acne vulgaris, moderate rate, before treatment; $\bar{B}$ - acne vulgaris, moderate rate, after treatment
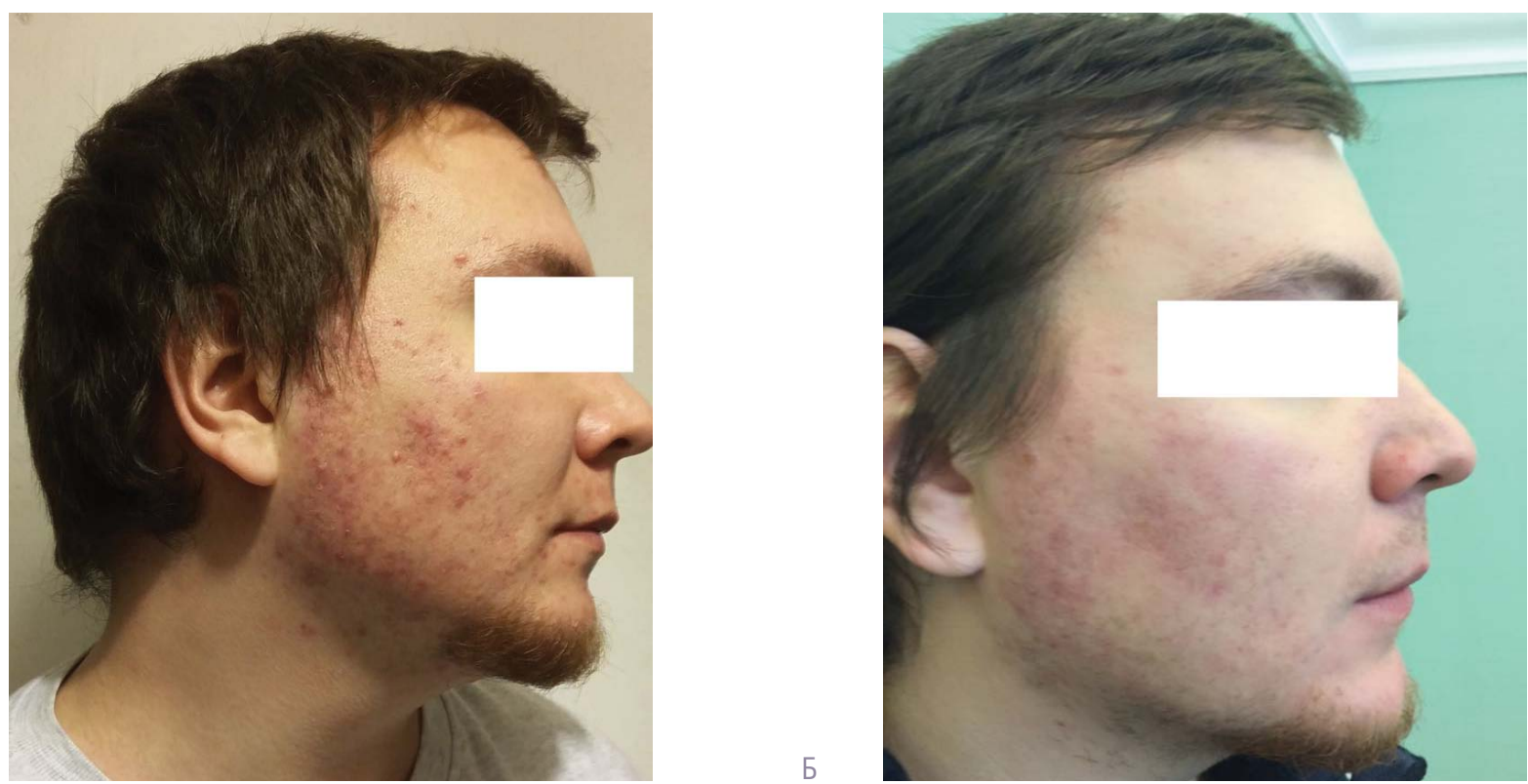

Рис. 3. Больной К., 23 года: А — вульгарные акне, тяжелая степень, до лечения; Б — вульгарные акне, тяжелая степень, после лечения

Fig. 3. Patient K., 23 years old. A — vulgaris acne, severe rate, before treatment; $\bar{B}$ - vulgaris acne, severe rate, after treatment 
Таблица 2. Показатели гемограммы больных вульгарными акне до и после лечения

Table 2. Hemogram indicators for patients with vulgar acne before and after treatment

\begin{tabular}{cccc}
\hline Показатель / единицы измерения & До лечения $(n=28)$ & После лечения $(n=28)$ & Нормальные показатели \\
\hline Эритроциты, $\times 10^{12} / л$ & $4,6 \pm 0,25$ & $4,68 \pm 0,52$ & $4,10-5,1$ \\
\hline Гемоглобин, г/л & $12,4 \pm 0,43$ & $13,0 \pm 0,51$ & $12,3-15,3$ \\
\hline Гематокрит, $\%$ & $38,3 \pm 2,31$ & $38,9 \pm 3,79$ & $35,0-47,0$ \\
\hline Лейкоциты, $\times 109 / л$ & $5,95 \pm 0,81$ & $5,87 \pm 1,92$ & $4,4-10,3$ \\
\hline Тромбоциты, $\times 10 \% / л$ & $240 \pm 29,4$ & $170-394$ \\
\hline СоЭ, мм/час & $230 \pm 31,9$ & $8,8 \pm 2,16$ & $1-20$
\end{tabular}

Таблица 3. Результаты исследования биохимических показателей крови у пациентов с вульгарными акне до и после лечения

Table 3. Examination of blood biochemical parameters in patients with vulgar acne before and after treatment

\begin{tabular}{|c|c|c|c|}
\hline & До лечения $(n=28)$ & После лечения $(n=28)$ & Нормальные показатели \\
\hline Глюкоза, ммоль/л & $5,08 \pm 0,14$ & $5,12 \pm 0,21$ & $4,1-5,9$ \\
\hline Креатинин, мкмоль/л & $70 \pm 3,13$ & $71,1 \pm 2,5$ & $44-97$ \\
\hline Общий белок, г/л & $69,33 \pm 1,61$ & $69,28 \pm 1,24$ & $57-82$ \\
\hline Общий билирубин, мкмоль/л & $13,8 \pm 1,18$ & $13,7 \pm 1,25$ & $5,0-21,0$ \\
\hline Мочевая кислота, мкмоль/л & $299,97 \pm 18,83$ & $299,84 \pm 17,9$ & $184-464$ \\
\hline Холестерин, ммоль/л & $4,58 \pm 0,26$ & $4,57 \pm 0,13$ & $3,20-5,18$ \\
\hline Триглицериды, ммоль/л & $2,09 \pm 0,23$ & $2,08 \pm 0,21$ & $0,00-2,83$ \\
\hline Аспартатаминотранссрераза, ЕД/л & $22,83 \pm 1,81$ & $21,9 \pm 1,89$ & $0-34$ \\
\hline Аланинаминотранссрераза, ЕД/л & $27,3 \pm 2,31$ & $27,46 \pm 2,35$ & $10-49$ \\
\hline Щелочная фоссфатаза, ЕД/л & $143,67 \pm 12,41$ & $143,52 \pm 12,12$ & $70-290$ \\
\hline Гамма-глютамилтранспептидаза, ЕД/л & $24,4 \pm 2,72$ & $24,38 \pm 2,16$ & $0-38$ \\
\hline Лактатдегидрогеназа, ЕД/л & $192,43 \pm 8,45$ & $188,46 \pm 8,86$ & $120-246$ \\
\hline
\end{tabular}

Полученные результаты исследования гемограммы и основных показателей обменных процессов в организме у пациентов свидетельствуют о том, что миноциклин является безопасным препаратом для терапии вульгарных акне.

При изучении дерматологического индекса качества жизни у пациентов со средней $(n=22)$ и тяжелой степенью $(n=6)$ до лечения среднее значение ДИКЖ составляло 19,4 $\pm 3,1$ и 21,9 $\pm 2,7$ балла соответственно, что соответствует сильному негативному влиянию заболевания на жизнь пациента. При этом значения ДИКЖ в обеих группах мало отличались друг от друга, что, вероятнее всего, объясняется тем, что высыпания и в том и другом случае локализуются в основном на лице и вызывают различные чувства (стыд, неловкость, застенчивость и др.) с формированием комплекса неполноценности и нередко ведения замкнутого образа жизни. После проведенного лечения среднее значение индекса снизилось до 1,8 \pm 0,2 и 3,4 \pm 0,3 балла (соответственно), т.е. ДИКЖ уменьшился в 10,8 раза у больных со среднетяжелыми формами вульгарных акне и в 6,4 раза - у больных с тяжелыми фрормами (различия статистически достоверны). Это свидетельствует о значительном улучшении качества жизни пациентов.

При исследовании морфологии кожи с помощью конфокальной лазерной сканирующей in vivo микроскопии (КЛСМ) в области патологических очагов, характерных для акне, у всех пациентов до лечения выявлялась неровность поверхности рогового слоя, представленного группами интенсивно окрашенных крупных полигональных клеток, разделенных между собой разветвленными темными линиями. В эпидермисе визуализировались расширенные устья сально-волосяных фолликулов (СВФ) с белым концентрическим веществом вдоль стенки, что говорит о наличии признаков фолликулярного гиперкератоза, одного из основных патегенетических факторов развития вульгарных угрей. Вокруг фолликулов отмечались признаки перифолликулярного иноильтрата. Глубже лежащие слои эпидермиса, зернистый, шиповатый и базальный, значительно не отличались от таковых в непораженной коже. Отмечалось расширение сосудов поверхностного сосудистого сплетения в очагах акне. Папулы представляли собой темные округлые структуры, заполненные внутри светлым аморфным содержимым и/или организованным воспалительным иноильтратом с высокой отражательной способностью. Для папул было характерно наличие значительного воспалительного инфильтрата в эпидермисе, в дерме отмечались выраженный экзоцитоз, воспалительная реакция и гиперваскуляризация.

Пустулы при конфокальной микроскопии выглядели как отверстия, внутри которых визуализировалась четко очерченная масса светлого аморфного вещества, окруженного темным пространством с рассеянным воспалительным инфильтратом и нечетко очерченными контурами, отделяющими его от окружающей кожи. 

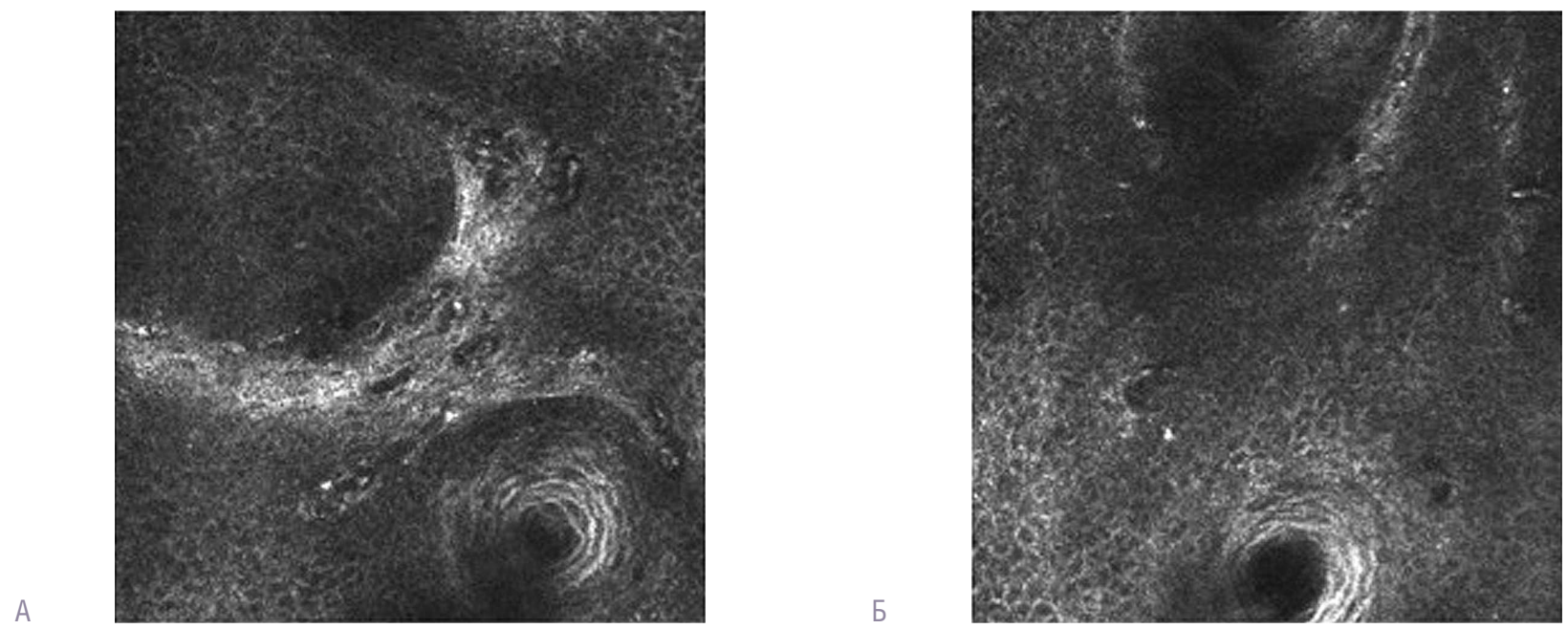

\begin{abstract}
Рис. 4. Конфокальная лазерная сканирующая in vivo микроскопия очага с клиническим проявлением вульгарного акне средней степени тяжести: А 一 до лечения: отмечаются расширенные сосуды, заметны фокусы воспалительных инфильтратов и небольшие участки фиброзирования; Б — через 1 месяц после лечения: уменьшение количества расширенных сосудов, участки воспаления отсутствуют

Fig. 4. Confocal laser scanning in vivo microscopy of a site with the clinical manifestation of moderate acne vulgaris: A — before treatment: dilated vessels, foci of inflammatory infiltrates and small areas of fibrosis; 5 - 1 month following treatment: a decrease in the number of dilated vessels, absence of inflammation areas
\end{abstract}

Сосуды и воспалительный инфильтрат всегда визуализировались по периферии элемента.

По результатам конфокальной лазерной сканирующей in vivo микроскопии, проведенной в динамике до и после лечения, отмечалось уменьшение признаков гиперкератинизации протоков СВФ и перифолликулярной инфильтрации, уменьшение количества расширенных сосудов, избытка волокнистых структур и признаков наличия воспалительного инфильтрата (рис. 4 А, Б).

По результатам анализа исследований методом лазерной доплеровской фрлометрии (ЛДФ) выявлено, что до лечения показатель микроциркуляции у всех обследуемых был повышен и составлял 11,8 \pm 1,2 перф. ед. при норме 8,3 \pm 0,4 перф. ед. Были выявлены нарушения по застойно-спастическому типу: показатель ALF/CKO × $100 \%$ составил 167,4 \pm 3,8 \% против $137,3 \pm 3,9 \%(p<0,01)$, что подтверждает гипертонус в артериолярном звене микроциркуляторного русла. Показатель AHF/CKO × 100 \%, характеризующий высокочастотные колебания, обусловленные изменением давления в венозном звене микроциркуляторного русла, вызванного дыхательными экскурсиями, составил: $122,3 \pm 3,5 \%$ против 65,9 $\pm 3,8 \%(p<0,001)$, что свидетельствует об увеличении давления и выраженных застойных явлениях в венулярном звене микроциркуляторного русла. Показатель АСF/CКО × $100 \%$ составил $55,1 \pm 1,6 \%$ при норме $33,7 \pm 2,4 \%(p<0,001)$, что говорит о снижении базального кровотока и наличии застойных явлений на уровне капилляров.

После проведенного лечения миноциклином показатели пассивного кровотока демонстрировали тенденцию к снижению ряда показателей: ПМ с 11,8 \pm 1,2 до 9,9 $\pm 1,07$ перф. ед. $(p<0,05)$; снижение ALF/ CKO $\times 100 \%$ с 167,4 \pm 3,8 до 148,3 $\pm 4,5 \%(p<0,01)$; $\mathrm{AHF} / \mathrm{CKO} \times 100 \%$ с 122,3 43,5 до 68,87 $\pm 2,5 \%(p<0,01)$; $\mathrm{ACF} / \mathrm{CKO} \times 100 \%$ с 55,1 $\pm 1,6$ до $39,4 \pm 1,7 \%(p<0,01)$.

В ходе исследования у двух пациентов отмечалась тошнота в первые дни приема лекарственного препарата Минолексин ${ }^{\circledR}$ в суточной дозе 100 мг, однако при снижении суточной дозы до 50 мг эти явления пре- кратились. Других нежелательных явлений не выявлено. Ни один пациент не выбыл из исследования во время курса лечения.

\section{Заключение}

1. Системный антибактериальный препарат Минолексин $^{\circledR}$ (миноциклин) высокоэффективен в лечении вульгарных акне средней и тяжелой степени, что подтверждается неинвазивными методами исследования (результатами себуметрии, конфокальной лазерной сканирующей микроскопии).

2. В результате проведенной терапии у 20 (91\%) больных вульгарными акне средней степени тяжести была достигнута клиническая ремиссия, у двух (9\%) больных - значительное улучшение. У 5 (83,3 \%) больных с тяжелым течением вульгарных акне отмечалось значительное улучшение и у одного больного $(16,7 \%)-$ улучшение. Лучшие результаты были получены у больных со средней степенью тяжести.

3. Качество жизни больных вульгарными акне значительно улучшается в результате лечения лекарственным препаратом Минолексин ${ }^{\circledR}$ (миноциклин), о чем свидетельствует редукция ДИКЖ (среднее значение индекса снизилось с 19,4 $\pm 3,1$ до 1,8 \pm 0,2 балла при средней степени тяжести и с 21,9 $\pm 2,7$ до $3,4 \pm 0,3$ балла при тяжелом течении вульгарных угрей).

4. Результаты лазерной доплеровской фрлоуметрии выявили снижение базального кровотока и наличие застойных явлений на уровне капилляров у больных вульгарными угрями, что указывает на тенденцию к формированию рубцов в местах воспалительных элементов. После курса лечения показатели ЛДФ нормализовались, что косвенно свидетельствует о возможной профилактике развития симптомокомплекса постакне под влиянием минолексина.

5. Терапия антибактериальным препаратом минолексин является безопасным, о чем свидетельствуют результаты клинического и биохимического исследований крови до и после лечения, а также отсутствие нежелательных явлений у больных. 
Таким образом, минолексин является высокоэффрективным и безопасным препаратом для лечения вульгарных акне средней и тяжелой степени тяжести и может быть рекомендован для практического применения в амбула- торной практике. Препарат обладает выраженным бактериостатическим эфрфектом и высоким уровнем липофильности, быстро проникает через липидный слой бактерий и интенсивно кумулируется в сальных железах.

\section{Литература/References}

1. Do T. T., Zarkhin S., Orringer J. S. Computer-assisted alignment and tracking of acne lesions indicate that most inflammatory lesions arise from comedones and de novo. J Am Acad Dermatol. 2008;58(4):603-608.

2. Kircik L. H. Revaluating treatment targets in acne vulgaris: adapting to a new understanding of pathophysiology. J Drugs Dermatol. 2014;13(6):S57-60.

3. Rocha M. A., Costa C. S., Bagatin E. Acne vulgaris: an inflammatory disease even before the onset of clinical lesions. Inflamm Allergy Drug Targets. 2014;13(3):162-167.

4. Beyot C., Auffret N., Poli F. et al. Propionibacterium acnes: an update on its role in the pathogenesis of acne. JEADV. 2014;3:271-278.

5. Leeming J., Holland K., Cunliffe W. J. The microbial colonization of inflamed acne vulgaris lesions. Br J Dermatol. 1988;118(2):203-208.

6. Zaleski-Larsen L. A., Fabi S. G., McGraw T., Taylor M. Acne Scar Treatment: A Multimodality Approach Tailored to Scar Type. Dermatol Surg. 2016 May;42(Suppl 2):139-149

7. Gollnick H. P., Graupe K., Zaumseil R. P. Comparison of combined azelaic acid cream plus oral minocycline with oral isotretinoin in severe acne. Eur J Dermatol. 2001;11(6):538-544.
8. Torok H. M. MD Extended-release Formulation of Minocycline in the Treatment of Moderate-to-severe Acne Vulgaris in Patients over the Age of 12 Years. J Clin Aesthet Dermatol. 2013 Jul;6(7):19-22.

9. Федеральные клинические рекомендации по ведению больных акне. M., 2015. [Federal Clinical Guidelines for Acne Patient Management. Moscow, 2015. (In Russ.)]

10. Анисимова М. Ю. Акне (acne vulgaris) с позиции доказательной медицины. Вестник репродуктивного здоровья. 2010 Декабрь:14-22. [Anisimova M. Yu. Acne (acne vulgaris) from the perspective of evidence-based medicine. Vestnik Reproductivnogo Zdorovya. 2010 December:14-22. (In Russ.)]

11. Острецова М. Н. Современный взгляд на проблему этиопатогенеза и классификации рубцовых проявлений симптомокомплекса постакне. Российский журнал кожных и венерических болезней. 2017;20(3):167-173. [Ostretsova M. N. A modern view of the problem of etiopathogenesis and classification of cicatricial manifestations of the postacne symptom complex. Russian Journal of Skin and Sexually Transmitted Diseases. 2017;20(3):167-173. (In Russ.)]

\section{Информация об авторе}

Елена Сергеевна Снарская - д.м.Н., просрессор кафедры кожных и венерических болезней Первого Московского государственного медицинского университета им. И. М. Сеченова (Сеченовский университет) Министерства здравоохранения Российской Федерации; е-таіl: snarskaya-dok@mail.ru

\section{Information about the author}

Elena S. Snarskaya - Dr. Sci. (Med.), Prof. of the Department of Skin and Venereal Diseases, I. M. Sechenov First Moscow State Medical University, Ministry of Health of the Russian Federation; e-mail: snarskaya-dok@mail.ru 